\title{
FAKTOR PENYEBAB TERJADINYA BURNOUTPADA MAHASISWA PROGRAM STUDI PENDIDIKAN DOKTER UNIVERSITAS ABULYATAMA
}

\author{
Anaiya Lutfia ${ }^{1}$, Ade Kiki Riezky ${ }^{1}$, Syarifah Nora Andriaty ${ }^{1}$ \\ ${ }^{1}$ Program Studi Pendidikan Dokter, Fakultas Kedokteran, Universitas Abulyatama
}

\begin{abstract}
Factors That Cause Burnout in Medical Education Study Program Students at Abulyatama University. Burnout is a condition of someone who has physical fatigue and psychological fatigue from the effect of work and emotional demands. To avoid burnout incidents, we make research about causative factors of burnout to medical students of Abulyatama University. The purpose of research is to know causative factors of burnout based on gender, origin, adaptation and study environment. The method used in this research amounted to 272 respondents. The results of the research can be seen from each of the causative factors including the male and female gender variables which are at an average value 4.11 and 3.74. While the regional origin variable gender and regional origin variables of regional do not affect the occurrence of burnout in medical students of the Abulyatama University. The adaptation variable abtained a significant value of 0.001 and the study environment obtained a significant 0.000 , from the significant value obtained from each factor obtained a significant value $<0.05$. This indicated that there is a relationship between adjustment and the study environment with the occurrence of burnout in medical students of the Abulyatama University.
\end{abstract}

Keywords: Burnout, Burnout Factors, Burnout

\begin{abstract}
Abstrak: Faktor Penyebab Terjadinya Burnout Pada Mahasiswa Program Studi Pendidikan Dokter Universitas Abulyatama.Burnout adalah kondisi seseorang yang mengalami kelelahan fisik dan psikologis akibat tuntutan pekerjaan dan emosional.Untuk menghindari terjadinya burnout maka dilakukan penelitian mengenai faktor penyebab terjadinya burnout yang dilakukan pada mahasiswa Program Studi Pendidikan Dokter Universitas Abulyatama.Penelitian ini bertujuan untuk mengetahui faktor penyebab burnout berdasarkan jenis kelamin, asal daerah, penyesuaian diri dan lingkungan pembelajaran. Metode yang digunakan pada penelitian ini adalah metode deskriptif analitik dengan pendekatan uji $F$. Sampelpada penelitian ini berjumlah 272 responden. Hasil penelitian dapat dilihat dari masing-masing faktor penyebab diantaranya variabel jenis kelamin laki- laki dan perempuan berada pada nilai rata-rata 4.11 dan 3.74.Sedangkan pada variabel asal daerah yang berasal dari daerah Kota Banda Aceh, Provinsi Aceh dan daerah luar Aceh berada pada nilai rata-rata 3.45, 3.86, dan 3.9. Hal ini menandakan bahwa variabel jenis kelamin dan asal daerah variabel tidak mempengaruhi terjadinya burnout pada mahasiswa Program Studi Pendidikan Dokter Universitas Abulyatama.Pada variabel penyesuaian diri memperoleh nilai signifikan 0.001 dan lingkungan pembelajaran memperoleh nilai signifikan 0.000 , dari nilai signifikan yang diperoleh dari masing-masing faktor didapatkan nilai signifikan $<0.05$. Hal ini menandakan bahwa adanya hubungan antara penyesuaian diri dan lingkungan pembelajaran dengan terjadinya burnout pada mahasiswa Program Studi Pendidikan Dokter Universitas Abulyatama.
\end{abstract}

Kata Kunci: Burnout, Faktor Penyebab Burnout, Gejala Burnout 


\section{PENDAHULUAN}

Mahasiswa kedokteran memiliki masalah psikologis lebih banyak akibat tekanan dibandingkan dengan jurusan lain. Hal ini dapat memicu munculnya penyakit psikologis seperti gangguan cemas dan stres.Stres selama pendidikan dokter memiliki dampak negatif pada kesehatan mental mahasiswa.Ketidakmampuan secara efektif dan konstruktif mengatasi stres berkontribusi terhadap terjadinya burnout.Burnout terjadi akibat reaksi terhadap kehidupan dan lingkungan yang menekan (Wani dan Qazi,2019).

Burnout adalah kondisi seseorang yang mengalami kelelahan fisik dan psikologis akibat tuntutan pekerjaan dan emosional.Burnout sering terjadi pada profesi terutama yang berhubungan dengan bidang jasa seperti dokter, perawat, dan guru (Dianti dan Findyartini, 2019).Apabila burnout terus terjadi dapat menimbulkan dampak negatif terkait dengan kepuasan hidup diantara pelajar dan profesional kesehatan.Kepuasan hidup adalah konsep kognitif seseorang mengenai kesejahteraan hidup yang baik, didefinisikan sebagai kesadaran individu untuk mengevaluasikan hidupnya berdasarkan pada standar yang ditetapkan oleh diri sendiri (Wang,et al., 2019).

Di dunia didapatkan satu dari dua mahasiswa kedokteran mengalami burnout bahkan sebelum masuk masa residensi. Penelitian yang dilakukan oleh Frajerman et al terkait "burnout in medical student before residency: Asystematic review and meta-analysis" yang melibatkan 17.431 mahasiswa seluruh dunia, didapatkan 8.060 diantaranya mengalami sindrom burnout. Prevalensi terjadinya burnouttertinggi terdapat pada komponen kelelahan emosional exhaustion (32,8- 48,9), komponen depersonalization $(31,5 \%)$, dan komponen personal accomplishment $(27,4 \%)$ (Frajerman,et al., 2019).

Hasil penelitian yang dilakukan pada mahasiswa kedokteran di Karachi, Pakistan (semester ketiga hingga semester terakhir) $18,2 \%$ dari setiap lima peserta satu diantaranya terkena sindrom burnout (Asghar,et al., 2019).Studi yang dilakukan diantara mahasiswa kedokteran Pakistan dan Swedia, pada tahun 2015 keduanya melaporkan prevalensi kelelahan 47\% pada populasi sampel mereka. Hasil penelitian yang dilakukan oleh Yumna et al sebanyak 777 mahasiswa kedokteran yang berpartisipasi, $447 \quad(57,5 \%)$ mahasiswa perempuan mengalami burnout, sedangkan pada mahasiswa laki-laki $330 \quad(42,5 \%)$ mengalami burnout. (Muzafar, et al., 2015).

Di Indonesia penelitian mengenai burnout dilakukan pada mahasiswa Program Studi Pendidikan Dokter semester 2, 4, dan 6 pada tahun 2018. Penelitian ini membagi pengukuran burnout kedalam empat kategori: burnout tingkat rendah, burnout tingkat sedang, burnout tingkat tinggi, dan burnout tingkat sangat tinggi, dari 262 sampel yang digunakan, $23.7 \%$ mengalami burnout tingkat tinggi, $56.9 \%$ mengalami burnout tingkat sedang, dan $29.8 \%$ mengalami burnout tingkat rendah (Nathania,2019). Penelitian yang sama juga dilakukan di Fakultas Kedokteran Universitas Indonesia didapatkan pada 164 mahasiswa semester pertama klinik diperoleh 35,3\% mahasiswa mengalami kelelahan emosional yang tinggi, dan $51,2 \%$ mahasiswa mengalami personal accomplishment(Dianti dan Findyartini, 2019).

Dari penelitian-penelitian sebelumnya, peneliti tertarik untuk melakukan penelitian dengan judul "Faktor Penyebab Terjadinya Burnout pada Mahasiswa Program Studi Pendidikan Dokter (PSPD) Universitas Abulyatama".Sampel pada penelitian ini adalah mahasiswa kedokteran Universitas Abulyatama pada tahap preklinik dan klinik.

\section{METODE}

Penelitian ini merupakan penelitian deskriptif analitik dengan desain penelitian pendekatan analisis univariat dan analisis bivariat.Penelitian ini bertujuan untuk mengetahuifaktor 
penyebab terjadinya burnout pada mahasiswa Program Studi Pendidikan Dokter Universitas Abulyatama pada tahap preklinik dan tahap klinik.

Penelitian dilaksanakan pada Maret-Juli tahun 2020 di Fakultas Kedokteran Universitas Abulyatama. Populasi dalam penelitian ini adalah mahasiswa Program Studi Pendidikan Dokter pada tahap preklinik dan tahap klinik di Universitas Abulyatama.Sampel penelitian yang diambil menggunakan metode total sampling pada seluruh mahasiswa pendidikan dokter Universitas Abulyatama yang telah sesuai dengan kriteria inklusi dan eksklusi sebagai berikut:

Kriteria Inklusidalam penelitian ini, yaitu:

a. Mahasiswa PSPD pada tahap preklinik.

b. Mahasiswa PSPD pada tahap klinik.

c. Mahasiswa yang tidak cuti akademik.

d. Mahasiswa yang bersedia mengisi kuesioner.

Kriteria Eksklusidalam penelitian ini, yaitu:

a. Mahasiswa yang sudah berumah tangga.

b. Mahasiswa yang tidak lengkap mengisi kuesioner.

Variabel yang diteliti terdiri atas variabel dependen, yaitu burnout pada mahasiswa Program Studi Pendidikan Dokter Universitas Abulyatama, dan variabel independen, faktor penyebab burnout seperti: jenis kelamin, asal daerah, penyesuaian diri, dan lingkungan pembelajaran.

Instrumen pengumpulan data dilakukan dengan menggunakan data primer berupa lembar kuesioner yang disusun dalam bentuk google form dan dibagikan secara daring kepada mahasiswa yang menjadi sampel dalam penelitian.

Analisis data dalam penelitian dilakukan dengan analisis univariat untuk memperoleh deskriptif statis dari masing-masing variabel(penyesuaian diri dan lingkungan pembelajaran) terhadap terjadinya burnout. Analisis ini juga dilakukan untuk melihat rata-rata burnout dari masing-masing variabel(jenis kelamin dan asal daerah). Output yang digunakan berupa nilai mean.

Analisis data dalam penelitian dilakukan dengan analisis bivariat untukmelihat kemungkinan adanya hubungan antara variabel independen yaitu faktor penyebab (jenis kelamin, asal daerah, penyesuaian diri dan lingkungan pembelajaran) terhadap variabel dependen yaitu burnout pada mahasiswa Program Studi Pendidikan Dokter Universitas Abulyatama.

\section{HASIL}

1. Karakteristik Responden

a. Karakteristik Responden Berdasarkan Jenis Kelamin

Pada penelitian ini responden dikelompokkan berdasarkan jenis kelamin.

Tabel 1.Distribusi Responden Berdasarkan Jenis Kelamin

\begin{tabular}{lcc}
\hline \multicolumn{1}{c}{ Jenis Kelamin } & Jumlah & Persen \% \\
\hline Laki-Laki & 70 & 26 \\
Perempuan & 202 & 74 \\
Total & 272 & 100 \\
\hline
\end{tabular}

Data pada tabel 1 menunjukkan berjenis kelamin perempuan. bahwa dari 272 responden terdapat 70 Berdasarkan data dapat dilihat bahwa orang $(26 \%)$ yang berjenis kelamin sebagian besar responden berjenis laki-laki dan 202 orang (74\%) lainnya kelamin perempuan. 


\section{b. Karakteristik Responden Berdasarkan Tahun Masuk Fakultas Kedokteran}

Pada penelitian ini responden ajaran masuk Fakultas Kedokteran dikelompokkan berdasarkan tahun Universitas Abulyatama.

Tabel 2. Distribusi Responden Berdasarkan Tahun Masuk Fakultas Kedokteran

\begin{tabular}{lccc}
\hline & Tahun Masuk & Jumlah & Persen \% \\
\hline Mahasiswa & 2019 & 53 & 19 \\
Preklinik & 2018 & 63 & 23 \\
& 2017 & 70 & 26 \\
Mahasiswa & 2016 & 49 & 18 \\
Klinik & 2015 & 37 & 14 \\
& & 272 & 100 \\
\hline
\end{tabular}

Pada tabel 2 menunjukkan bahwa responden yang diteliti terbagi menjadi dua yaitu mahasiswa preklinik dan mahasiswa klinik. Pada mahasiswa preklinik angkatan 2017 sebanyak 70 orang $(26 \%)$, sedangkan pada mahasiswa preklinik angkatan 2018 sebanyak 63 orang $(23 \%)$, dan mahasiswa preklinik pada angkatan 2019 sebanyak 53 orang (19\%), dengan total responden dari mahasiswa preklinik sebanyak 186 responden.

Pada mahasiswa klinik angkatan 2015 sebanyak 37 orang (14\%), dan mahasiswa klinik pada angkatan 2016 sebanyak 49 orang $(18 \%)$, total responden dari mahasiswa klinik sebanyak 86 orang. Total responden keseluruhan dari mahasiswa preklinik dan mahasiswa klinik adalah 272 responden.

\section{c. Karakteristik Responden Berdasarkan Asal Daerah}

Pembagian responden Kota Banda Aceh, responden yang berdasarkan asal daerah terdiri dari berasal dari Provinsi Aceh dan tiga, yaitu responden yang berasal dari responden yang berasal dari luar Aceh.

Tabel 3. Distribusi Responden Berdasarkan Asal Daerah

\begin{tabular}{cccc}
\hline No & Asal Daerah & Jumlah & Persen \% \\
\hline 1 & Kota Banda Aceh & 29 & 11 \\
2 & Provinsi Aceh & 167 & 61 \\
3 & Luar Aceh & 76 & 28 \\
& Total & 272 & 100 \\
\hline
\end{tabular}

Data pada tabel 3 menunjukkan bahwa dari 272 responden terdapat 29 orang $(11 \%)$ yang berasal dari Kota Banda Aceh, 167 orang (61\%) yang berasal dari Provinsi Aceh, dan 76 orang (28\%) yang berasal dari luar Aceh. Dari data di atas dijelaskan bahwa banyak responden yang berasal dari Provinsi Aceh dan luar Aceh dan hanya sedikit responden yang berasal dari Kota Banda Aceh. 


\section{Burnout}

a. Pengkajian Burnout Menggunakan MBI

Tabel 4. Pengkajian Burnout Menggunakan MaslachBurnout Inventory(MBI)

\begin{tabular}{lcccc}
\hline & Jumlah & Minimum & Maximum & Mean \\
\hline Burnout & 272 & 1 & 9 & 3.84 \\
\hline
\end{tabular}

Pengkajian burnout menggunakan maslach burnout inventorypada tabel 4 menunjukkan bahwa dari 272 responden, rata-rata memiliki nilai burnout (skor MBI) 3.84, skor ini menandakan bahwa responden perlu memonitor situasi, sedangkan pada nilai minimum terdapat pada skor satu yang berarti ada beberapa responden yang menjawab pada nilai kecil yaitu satu dan pada nilai maximum terdapat pada skor sembilan yang berarti responden tersebut berada pada sinyal merah dan perlu adanya pemantauan.

\section{b. Hubungan Jenis Kelamin dengan Terjadinya Burnout}

Tabel 5. Hubungan Jenis Kelamin dengan Terjadinya Burnout

\begin{tabular}{lccc}
\hline Jenis Kelamin & Mean & Jumlah & Keterangan \\
\hline Laki-Laki & 4.11 & 70 & Tidak Burnout \\
Perempuan & 3.74 & 202 & Tidak Burnout \\
\hline
\end{tabular}

Hubungan jenis kelamin dengan terjadinya burnout terbagi menjadi duayaitu hubungan jenis kelamin lakilaki dengan terjadinya burnout dan hubungan jenis kelamin perempuan dengan terjadinya burnout.Pada tabel 5 menunjukkan hubungan jenis kelamin laki-laki dengan terjadinya burnout rata-rata terdapat pada nilai 4.11 , dan hubungan jenis kelamin perempuan dengan terjadinya burnout memiliki rata-rata 3.74 .

\section{c. Hubungan Asal Daerah dengan Terjadinya Burnout}

Tabel 6. Hubungan Asal Daerah dengan Terjadinya Burnout

\begin{tabular}{lccc}
\hline \multicolumn{1}{c}{ Asal Daerah } & Mean & Jumlah & Keterangan \\
\hline Kota Banda Aceh & 3.45 & 29 & Tidak Burnout \\
Provinsi Aceh & 3.86 & 167 & Tidak Burnout \\
Daerah Luar Aceh & 3.95 & 76 & Tidak Burnout \\
\hline
\end{tabular}

Hubungan asal daerah dengan terjadinya burnout terbagi menjadi tiga yaitu hubungan asal daerah Kota Banda Aceh dengan terjadinya burnout, hubungan asal daerah Provinsi Aceh dengan terjadinya burnout, dan hubungan daerah luar Aceh dengan terjadinya burnout. Pada tabel 6 menunjukkan hubungan asal daerah
Kota Banda Aceh dengan terjadinya burnout rata-rata berada pada nilai 3.45, sedangkan hubungan asal daerah pada Provinsi Aceh dengan terjadinya burnout rata-rata berada pada nilai 3.86 dan hubungan asal daerah yang berada di luar Aceh rata-rata berada pada nilai 3.95 . 


\section{d. Hubungan Penyesuaian Diri dengan Terjadinya Burnout}

Tabel 7. Hubungan Penyesuaian Diri dengan Terjadinya Burnout

\begin{tabular}{lcc}
\hline & Nilai Sig & Hasil \\
\hline $\begin{array}{l}\text { Hubungan Penyesuaian Diri Dengan } \\
\text { Terjadinya Burnout }\end{array}$ & 0.001 & Burnout \\
\hline
\end{tabular}

Hubungan faktor penyebab burnout pada tabel 7 memiliki nilai
penyesuaian diri dengan terjadinya signifikan 0.001 .

\section{e. Hubungan Lingkungan Pembelajaran dengan Terjadinya Burnout}

Tabel 8. Hubungan Lingkungan Pembelajaran dengan Terjadinya Burnout

\begin{tabular}{lcc}
\hline & Nilai Sig & Hasil \\
\hline $\begin{array}{l}\text { Hubungan Lingkungan Pembelajaran } \\
\text { Dengan Terjadinya Burnout }\end{array}$ & 0.000 & Burnout \\
\hline
\end{tabular}

Hubungan faktor penyebab lingkungan pembelajaran dengan

\section{PEMBAHASAN}

Tabel 4 menunjukkan bahwa dari 272 mahasiswa Program Studi Pendidikan Dokter Universitas Abulyatama yang menjadi responden penelitian rata-rata memiliki level (skor maslach burnout inventory) 3.84.Skor maslach burnout inventory memiliki rentang antara 0 sampai 10 , dimana 0 menunjukkan kondisi tidak burnout dan 10 adalah sangat burnout. Skor yang diperoleh pada penelitian ini menunjukkan bahwa level burnout responden berada dalam tahap perlunya memonitor situasi yang dihadapi (Mizmir, 2011).

Terdapat beberapa faktor yang menyebabkan burnout pada mahasiswa Program Studi Pendidikan Dokter Universitas Abulyatama berada pada level agak rendah dan perlunya tahap memonitor situasi yang dihadapi. Faktor -faktor yang mempengaruhi meliputi jenis kelamin dan asal daerah.Hal tersebut masuk kedalam kategori penyebab faktor demografi yang berasal dari mahasiswa itu sendiri.

\section{Hubungan Jenis Kelamin dengan Terjadinya Burnout}

Pada variabel jenis kelamin di dapatkan nilai rata-rata responden yang berjenis kelamin laki-laki berada pada terjadinya burnout pada tabel 8 memiliki nilai signifikan 0.000 .

nilai 4.11, sedangkan pada responden perempuan berada pada nilai rata-rata 3.74. Skor yang diperoleh pada penelitian ini menunjukkan bahwa level burnout responden berada dalam tahap perlunya memonitor situasi yang dihadapi (Mizmir, 2011).

Hal ini menandakan bahwa jenis kelamin laki-laki lebih mudah mengalami burnout dari pada jenis kelamin perempuan.Hasil ini sejalan dengan penelitian Sopiati yang menunjukkan bahwa jenis kelamin lakilaki lebih mudah mengalami burnout daripada perempuan. Hal ini disebabkan karena perempuan lebih lentur dan lebih mampu menangani tekanan-tekanan besar, sedangkan laki-laki lebih kaku dan serius dalam menghadapi masalah. Sehingga rata-rata skor total maslach burnout inventorypada mahasiswa Program Studi Pendidikan Dokter Universitas Abulyatama menjadi agak rendah (Alimah, 2016).

\section{Hubungan Asal Daerah dengan Terjadinya Burnout \\ Berdasarkan asal daerah} responden yang berasal dari daerah Kota Banda Aceh berada pada nilai ratarata 3.45, responden yang berasal dari Provinsi Aceh berada pada nilai ratarata 3.86 dan responden yang berasal 
pada dari daerah luar Aceh berada pada nilai rata-rata 3.95. Skor yang diperoleh pada penelitian ini menunjukkan bahwa level burnout responden berada dalam tahap perlunya memonitor situasi yang dihadapi. Hal ini menandakan responden yang berasal dari luar Aceh memiliki nilai lebih tinggi terkena burnout, kemudian diikuti oleh asal daerah yang berada disekitar Aceh dan yang paling rendah berada pada Kota Banda Aceh, hal ini disebabkan karena responden yang berasal dari Provinsi Aceh dan luar Aceh adalah mahasiswa yang bukan berasal dari Kota Banda Aceh.

Hasil ini sejalan dengan penelitian Sopiati yang menunjukkan bahwa mahasiswa perantauan lebih mudah terkena burnout dikarenakan pada proses pendewasaan dalam mencapai kesuksesan, mahasiswa perantauan dihadapkan pada berbagai aspek kehidupan yang membutuhkan kepercayaan diri, mandiri serta banyak penyesuaian. Ketika mahasiswa tidak memiliki penyesuaian diri maka hal itu berdampak pada terguncangnya emosi, kecemasan, ketidakmampuan dan keluhan terhadap nasib yang dialami.Hal itu pula yang dapat menyebabkan mahasiswa perantau lebih mudah mengalami burnout (Alimah, 2016).

Faktor lain yang mempengaruhi level burnout pada mahasiswa Program Studi Pendidikan Dokter Universitas Abulyatama adalah penyesuaian diri dan lingkungan pembelajaran.

\section{Hubungan Penyesuaian Diri dengan Terjadinya Burnout}

Pada variabel penyesuaian diri diperoleh hasil nilai signifikan 0.001 yaitu nilai signifikan kurang dari 0.05. Hal ini menandakan bahwa penyesuaian diri berhubungan dengan terjadinya burnout pada mahasiswa Program Studi Pendidikan Dokter Universitas Abulyatama.Hal ini dikarenakan terjadi transisi dari sekolah menengah atas atau sederajat ke perguruan tinggi membuat mahasiswa berada pada perubahan dan tuntutan, sehingga diperlukan adanya
penyesuaian.Mahasiswa yang memiliki penyesuaian diri terhadap tuntutan akademik, memiliki kecenderungan rendah terhadap terjadinya stres dan burnout.Kondisi tersebut membuat mahasiswa harus mampu untuk menyesuaikan diri dengan lingkungan belajar dan teknik pengajaran baru (Gavinta dan Hartati, 2015).

\section{Hubungan Pembelajaran Terjadinya Burnout}

Pada variabel lingkungan pembelajaran diperoleh hasil nilai signifikan 0.000 yaitu nilai signifikan kurang dari nilai alpha 0.05. Hal ini menandakan bahwa lingkungan pembelajaran berhubungan dengan terjadinya burnout pada mahasiswa Program Studi Pendidikan Dokter Universitas Abulyatama.

Dalam Pendidikan Kedokteran mahasiswa harus mampu mengarahkan diri sendiri pada pembelajaran dengan menggunakan pendekatan yang mendalam.Struktur kurikulum yang digunakan sejak tahun 2010 mengacu pada SK Mendiknas no.045/U/2002 tentang kurikulum berbasis kompetensi yaitu kurikulum dengan sistem Blok. Berdasarkan hal tersebut, mahasiswa diharapkan dapat mengatur waktu seefektif mungkin, karena waktu untuk menyelesaikan dalam satu blok cukup singkat, sehingga sistem pembelajaran pun akan menjadi cukup padat (Alimah, 2016).

\section{KESIMPULAN}

Berdasarkan tujuan dari penelitian ini maka diperoleh hasil kesimpulan bahwa faktor penyebab (jenis kelamin dan asal daerah) tidak mempengaruhi terjadinya burnout pada mahasiswa Program Studi Pendidikan Dokter Universitas Abulyatama, sedangkan pada faktor penyebab (penyesuaian diri dan lingkungan pembelajaran) mempengaruhi terjadinya burnout pada mahasiswa Program Studi Pendidikan Dokter Universitas Abulyatama. 
SARAN

Dari hasil penelitian yang dilakukan dan berdasarkan keterbatasan penelitian, saran-saran yang dapat dikemukakan yaitu, padapenelitian selanjutnya diharapkan dapat menggunakan faktor penyebab di luar faktor penyebab yang digunakan pada penelitian ini. Hasil dari penelitian ini juga diharapkan dapat menjadi sumber informasi bagi mahasiswa agar lebih sadar terhadap gejala-gejala yang Alimah, S.(2016). Gambaran Burnout pada Mahasiswa Jurusan Keperawatan Fikes Universitas Jendral Soedirman. Keperawatan Soedirman.

Asghar, A.A., Faiq, A., Shafique, S., Siddiqui, F., Asghar, N., Malik, S., et al. (2019). Prevalence and Predictors of the Burnout Syndrome in Medical Students of Karachi, Pakistan. Cureus 11(6). doi:10.7759/cureus.4879.

Dianti, N.A., dan Findyartini, A. (2019). Hubungan Tipe Motivasi terhadap Kejadian Burnout pada Mahasiswa Fakultas Kedokteran Universitas Indonesia pada Masa Transisi dari Pendidikan Preklinik ke Klinik Tahun 2018.Jurnal Kedokteran Indonesia 7 (2). doi: 10.23886/ejki.7.10771.

Frajerman, A., Morvan, Y., Krebs, M.O., Gorwood, P., dan Chaumette, B. (2019). Burnout in Medical Students Before Residency : A Systematic Review and MetaAnalysis. European Psychiatry 55: 36-42.

doi: 10.1016/j.eurpsy.2018.08.00 6.

Gavinta, D.A.P., dan Hartati, S. (2015) Asertivitas dan Penyesuaian Diri pada Mahasiswa Tahun Pertama Fakultas Kedokteran. Jurnal Empati 4(4):139-143.

Mizmir. (2011). Hubungan Burnout dengan Kepuasan Kerja Perpustakaan Nasional Republik Indonesia. Fakultas IImu Budaya Universitas Indonesia.

Muzafar, Y., Khan, H.H., Ashraf, H., Husaain, W., Sajid, H., Tahir, M., et al. (2015). Burnout and its menyebabkan burnout dengan melakukan pencegahan seperti, pelatihan mindfulness, manajemen stres, terapi relaksasi, diskusi kelompok kecil, mengembangkan kualitas mahasiswa juga memiliki efek positif pada kelelahan dan kepuasan diantara mahasiswa, agar terhindar dari terjadinya burnout.

\section{DAFTAR PUSTAKA}

Associated Factors in Medical Students of Lahore, Pakistan. Cureus 7(11).doi: 10.7759/cureus.390.

Nathania, A., Dinata, I.M.K., danGriadhi, I.P.A. (2019). Hubungan stres terhadap kelelahan pada mahasiswa Fakultas Kedokteran Universitas Udayana.Intisari Sains Medis 10(1): 134-138. doi: 10.1556/ism.v10i1.400.

Shah, A., Wyatt, M., Gourneau, B., Shih, G., dan De Ruyter, M. (2019). Emotional Exhaustion Among Anesthesia Providers at a Tertiary Care Center Assessed Using the MBI Burnout Survey. Psychology Health and Medicine 24(5): 620-624. doi: 10.1080/13548506.2018.154601 9.

Wang, Q., Wang, L., Shi, M., Lie, Xuenlian., Liu, R., Liu, J., et al. (2019). Empathy, Burnout, Life Satisfaction, Correlations and Associated Socio-Demographic Factors Among Chinese Undergraduate Medical Students: An Exploratory Cross-Sectional Study. BMC Medical Education 19(1): 1-10. doi: 10.1186/s12909-019-1788-3.

Wani, R.T., dan Qazi, T.B. (2019). Epidemiology of Burnout and Stress Among Medical Students of Undergraduate School and Its Associated Factors. Jurnal of Evidence-Based Medicine 6(28): 1907-1912. doi: 10.18410/jebmh/2019/389. 